\section{Endoscopic Balloon Sphincteroplasty: Use in a Patient with a Billroth II Gastrectomy}

A 76-year-old woman who had previously undergone a B-II gastrectomy presented for endoscopic retrograde cholangiopancreatography (ERCP) following episodes of pancreatitis. Diagnostic cholangiography demonstrated the presence of several small stones (less than $1 \mathrm{~cm}$ ) within the lower common bile duct. A shark-fin sphincterotome (Wilson-Cook, $6 \mathrm{Fr}, 200 \mathrm{~cm}$ long) could not be satisfactorily positioned to allow safe endoscopic biliary sphincterotomy, due to difficulty in orientating the sphincterotome. A $0.35-\mathrm{mm}$ guide wire was passed into the bile duct, and a deflated Meadox Olbert balloon-tipped catheter (total length $180 \mathrm{~cm}$, balloon length $4 \mathrm{~cm}$ ) was passed over the guide wire into the common bile duct (Figure 1) . The balloon was inflated to a diameter of $6 \mathrm{~mm}$ at a maximum pressure of 12 atmospheres for one minute. After 30 seconds' deflation, the balloon was reinflated for a further minute. The bile duct was cleared by trawling with a Keymed balloon. There were no complications, and the patient was discharged within 24 hours.

Staritz et al. (1) were the first to report percutaneous balloon dilation of the papilla of Vater in 15 patients, without complications. More recently, MacMathuna et al. (2) reported on a series of patients undergoing endoscopic sphincteroplasty; clearance of the bile duct was achieved in $79 \%$, with a complication rate of $4 \%$ (one patient developed pancreatitis). To our knowledge, there have been no previous reports of endoscopic balloon sphincteroplasty in patients who have previously undergone Billroth II gastrectomies. The difficulty in orientating the duodenoscope and sphincterotome in patients with an afferent loop are well known to experienced biliary endoscopists, and make the use of balloon sphincteroplasty particularly useful in this group of patients. Using endoscopic balloon sphincteroplasty, we were able to avoid the dangers of alternative procedures, such as combined endoscopic percutaneous procedures (3), or surgery. We suggest that balloon sphincteroplasty should be considered for other similar cases.

\section{J. A. Tibble, S. R. Cairns}

Dept. of Gastroenterology, Royal Sussex County Hospital, Brighton, United Kingdom

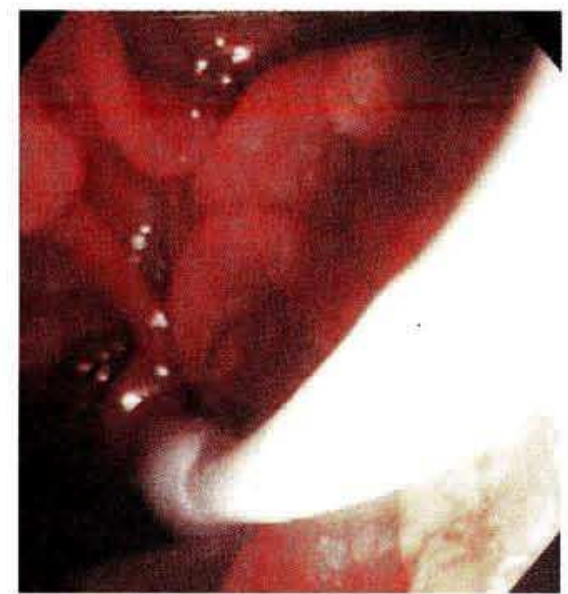

Figure 1: Endoscopic placement of a balloon across the sphincter of Oddi.

\section{References}

1. Staritz M, Ewe K, Meyer zum Buschenfelde KH. Endoscopic papillary dilatation for the treatment of common bile duct stones and papillary stenosis. Endoscopy 1983; 15: 197-8.

2. MacMathuna P, White P, Clarke E, et al. Endoscopic sphincteroplasty: a novel and safe alternative to papillotomy in the management of bile duct stone. Gut 1994; 35: 127-9.

3. Dowsett JF, Vaira D, Hatfield AR, et al. Endoscopic biliary therapy using the combined percutaneous and endoscopic technique. Gastroenterology 1989; 96: 1180-6.

Corresponding Author

S. R. Cairns, M.D.

Dept. of Gastroenterology

Royal Sussex County Hospital

Eastern Road

Brighton BN25BE

United Kingdom

Fax:+44-12 73-622906 